\title{
MIMO Antenna for UWB with Single Tuned Frequency Notched Characteristics using Parasitic Element Method
}

\author{
Punna Bharghava, N. Srikanta, Pachiyaannan Muthusamy
}

\begin{abstract}
A MIMO antenna with micro strip fed ultra wide band nature with characteristics of single band notching is presented in this paper. MIMO antenna has two monopole antennas. Larger impedance bandwidth is obtained by providing slots beside the feed line on ground plane. By using parasitic element on back side of patch band notching characteristics cab be obtained. Here, antenna size is $44 x 22 \times 1.6 \mathrm{~mm}^{3}$. This antenna operates over the frequency band $4 \mathrm{GHz}$ to $11 \mathrm{GHz}$ with notched frequency band $5.1 \mathrm{GHz}$ to $5.9 \mathrm{GHz}$. By keeping two monopole antennas perpendicular to each other, isolation of less than $15 d B$ is obtained and good value of ECC is obtained.
\end{abstract}

Keywords-Band notched characteristics, micro strip fed monopole antennas, MIMO antennas, parasitic element, Ultra wide band ( $\mathrm{UWB})$ antenna

\section{INTRODUCTION}

UWB technology has been utilizing for systems of communications. The challenge is that designing of antenna with UWB nature. Printed monopole antennas are used for UWB provided by FCC [1]. The impedance bandwidth enhancement can be accomplished by using notches at the lower corners of radiator [2], providing a slot in the radiating element of tapered nature [3], having the notch based structure in the plane of ground [2], [3]. But UWB frequency range involves interference to wireless communication systems like WLAN $(5.15 \mathrm{GHz}-5.35 \mathrm{GHz})$, so band stop nature is required in UWB frequency range.

Using U-shaped inverted parasitic element which is backside of patch, band notching characteristics is accomplished. By having two slots on both sides of feed on ground, larger bandwidth is accomplished. Simulated results are provided.

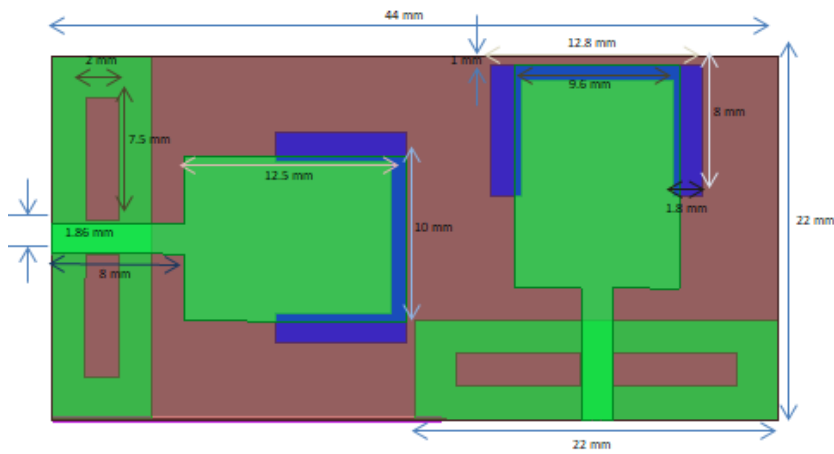

Fig. 1.MIMO Antenna structure

Revised Manuscript Received on December 15, 2019

Punna Bharghava, RF \& Microwave Laboratory VFSTR Deemed to be University Guntur,India. punnabharghava@gmail.com

N. Srikanta, RF \& Microwave Laboratory VFSTR Deemed to be University Guntur,India. nsriphd@ gmail.com

Pachiyaannan Muthusamy, RF \& Microwave Laboratory VFSTR Deemed to be University Guntur,India. pachiphd@gmail.com

\section{Monopole AnTEnNa DeSign}

The proposed monopole antenna given in Figure 1 consists of two monopole antennas. Each monopole antenna consists of rectangular shaped patch in simple form and ground plane of two slots and U-shaped parasitic element in inverted form. The Fr4 material is used as substrate with thickness of $1.6 \mathrm{~mm}$. The Fr4 has 4.4 as the value of relative permittivity. The width of micro strip feed line is fixed at $1.86 \mathrm{~mm}$ to have $50 \Omega$ characteristic impedance. The size of $10 \times 13.5 \mathrm{~mm}^{2}$ patch in rectangular shape is printed on substrate. The gap between patch and ground is $2 \mathrm{~mm}$ and ground length is $6 \mathrm{~mm}$. Ground is printed on back side of substrate.

The DGS provides additional current path and inductance and capacitance of the input impedance which leads to change bandwidth. More improved bandwidth can be accomplished by having changes in length and width of slots. As given in figure 1, the inverted U-shaped parasitic element is placed under rectangular patch and is also placed symmetrically. The inverted U-shaped parasitic element can perturb the response of resonance and it can act as half-wave resonant structure in parasitic form, which is electrically coupled to monopole rectangular structure [4].

\section{DESIGN OF MIMO ANTENNA}

The above mentioned monopole radiator is taken as radiator on MIMO antenna system. Two radiators have been taken to form MIMO system. Two line feeds are used for excitation of two radiators. To get high isolation or low mutual coupling, the radiators have to be placed perpendicular to each other [6]. The corresponding structure is shown in figure 1 .

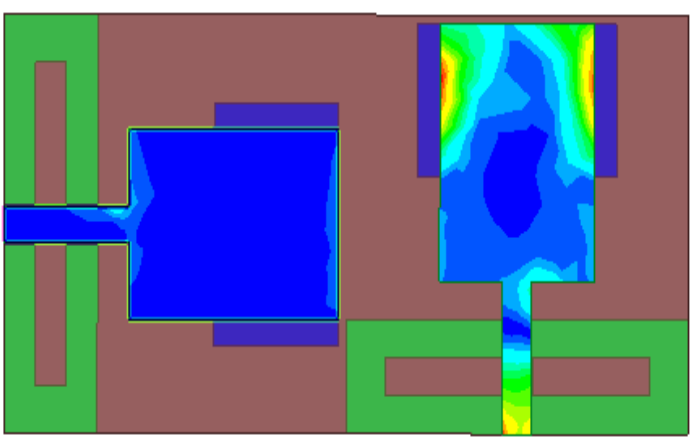




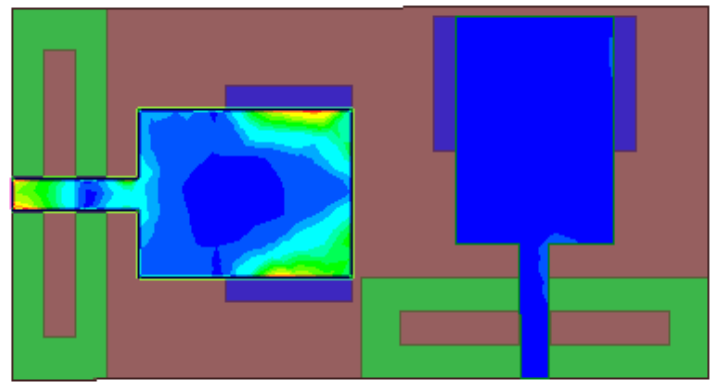

Fig 2. Input applied at port1 and port 2 individually and other is terminated with $\mathbf{5 0 \Omega}$

It is observed that when port- 1 is excited and port- 2 is terminated with $50 \Omega$ then current is accumulated only around radiator- 1 and when port- 2 is excited with supply and port-1 is terminated or loaded with $50 \Omega$ load then the current is accumulated only around radiator-2.

\section{Results \& Discussion}

The return loss plot is represented in figure 3. By observing return loss plot, it can be noted that there is notched frequency band $5.5 \mathrm{GHz}$ to $6.5 \mathrm{GHz}$.

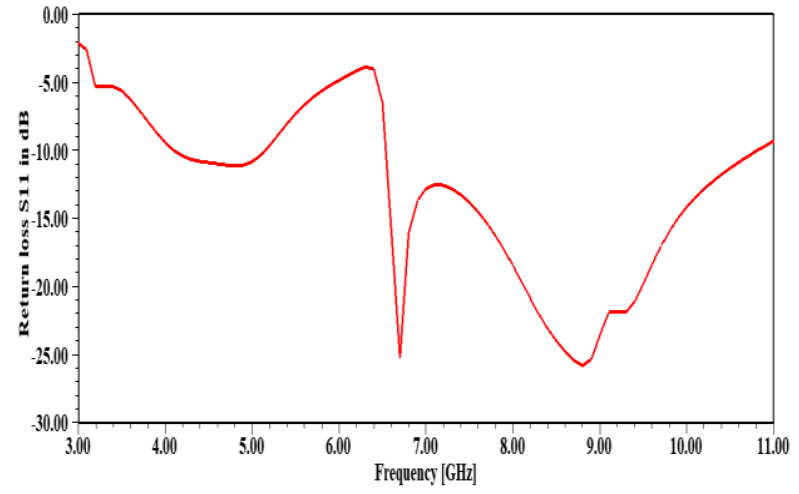

Fig 3. Return loss $S_{11}$ in $\mathbf{d B}$

By observing isolation plot $S_{21}$, the conclusion on mutual coupling can be found. From the plot, it is indicated that good value of isolation is achieved. In notched frequency band, the isolation value is higher about $-30 \mathrm{~dB}$.

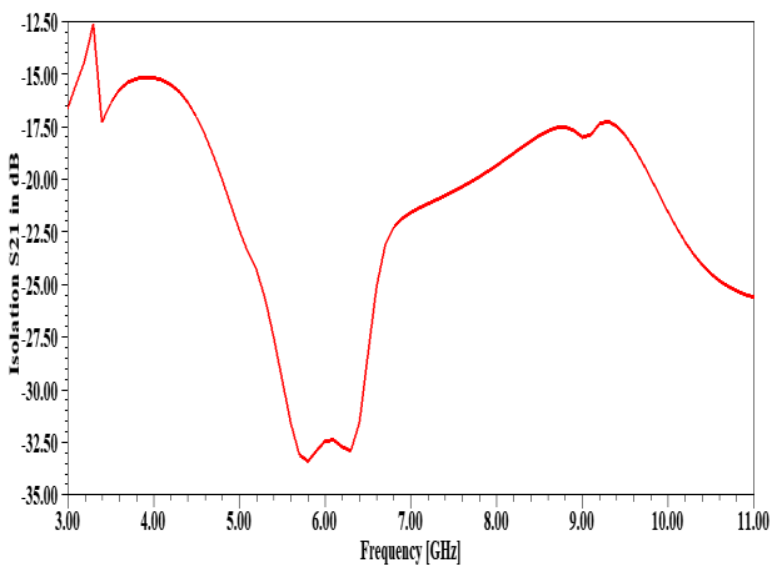

Fig 4. Isolation plot $S_{21}$ in $\mathbf{d B}$

The impedance matching characteristics can also be indicated using VSWR plot given in figure 5.

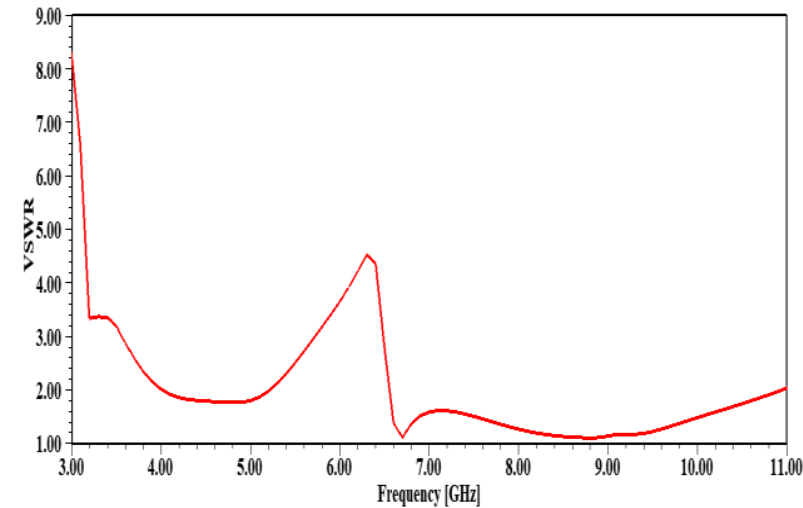

Fig 5. VSWR Plot

Form the gain plots measured at $\mathrm{phi}=0$ degrees and $\mathrm{phi}=$ 90 degrees it is understood that omnidirectional pattern is obtained.

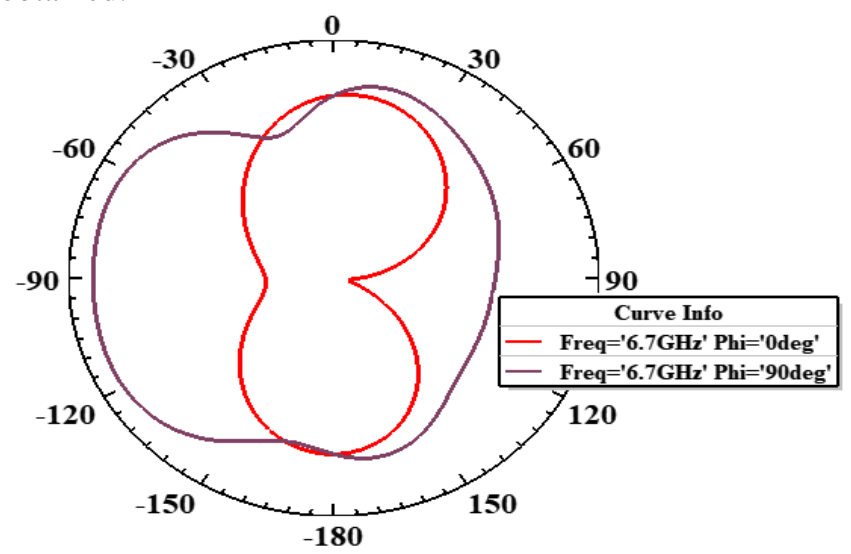

Fig 6. Gain plot

The envelope correlation coefficient ECC is to be very less to have independent nature of patterns

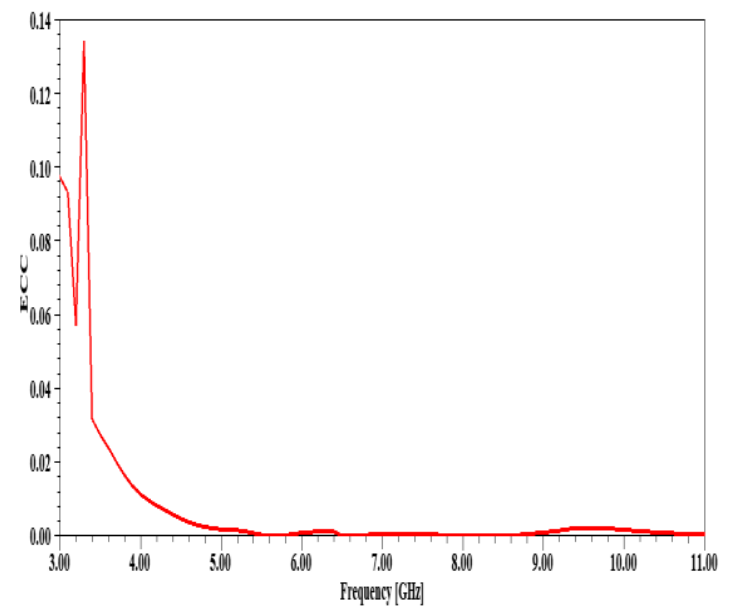

Fig 7. ECC plot

\section{CONCLUSION}

A UWB based MIMO antenna with band notched characteristics is presented. Increased bandwidth is provided by slots along the line feeding. Inverted U-shaped parasitic element provides band notched characteristics.

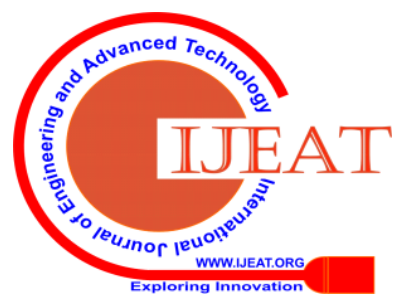


Envelope Correlation Coefficient of 0.005 is achieved and which is good amount of value represents that two radiators are independent.

\section{ACKNOWLEDGMENT}

We would like to acknowledge ANSYS software company and VFSTR (Deemed to be university). The RF \& Microwave laboratory in ECE department of VFSTR University is provided with good facilities for research in antenna design. The antenna simulation software -High Frequency Structure Simulator is provided by ANSYS.

\section{REFERENCES}

1. FCC, F., "First report and order on ultra-wideband technology," 2002

2. Jung, Jihak, Wooyoung Choi, and Jaehoon Choi. "A small wideband microstrip-fed monopole antenna." IEEE microwave and wireless components letters 15, no. 10 (2005): 703-705.

3. Verbiest, Joeri R., and Guy AE Vandenbosch. "A novel small-size printed tapered monopole antenna for UWB WBAN." IEEE Antennas and Wireless Propagation Letters 5 (2006): 377-379. K. Elissa, "Title of paper if known," unpublished.

4. Pan, Chien-Yuan, Tzyy-Sheng Horng, Wen-Shan Chen, and ChienHsiang Huang. "Dual wideband printed monopole antenna for WLAN/WiMAX applications." IEEE Antennas and Wireless Propagation Letters 6 (2007): 149-151.

5. Kim, K-H., Y-J. Cho, S-H. Hwang, and S-O. Park. "Band-notched UWB planar monopole antenna with two parasitic patches." Electronics Letters 41, no. 14 (2005): 783-785.

6. Liu, Li, S. W. Cheung, and T. I. Yuk. "Compact MIMO antenna for portable devices in UWB applications." IEEE Transactions on antennas and propagation 61, no. 8 (2013): 4257-4264. 